\title{
School injuries in an occupational health perspective: what do we learn from community based epidemiological studies?
}

\author{
Lucie Laflamme, Ewa Menckel
}

\begin{abstract}
Objective-The paper reviews community based epidemiological studies of injuries at school. It discusses their main findings in the light of a frame of analysis that emphasizes multidimensionality of causes, and in a Swedish context, where school injuries are legally regarded as occupational injuries.
\end{abstract}

Methods - A frame of analysis, inspired by research in the arena of occupational accident, was developed. It employs four key concepts to distinguish between injury and accident sequence, and between situational and structural factors as potential injury determinants. It also stresses the interaction between pupil, school, and community, in injury genesis. In parallel, a review of community based epidemiological studies of school injuries was undertaken after searching the relevant literature. The knowledge gathered from these studies is appraised in the light of the frame of analysis.

Results - In general, the studies point to potential risk groups, and to hazardous locations and activities. They address injury characteristics, but largely fail to define typical mechanisms. The literature sheds little light on whether there are particular characteristics of the community, school, or pupil(s) - other than gender and age - that influence injury event occurrence.

Conclusions-Further research should devote attention to the sequences of events culminating in school injuries, and to the structural determinants of accident sequences. In this, surveillance systems might prove to be of great utility.

(Injury Prevention 1997; 3: 50-56)

Keywords: school injuries; pupil injuries; injury surveillance; injury model.

Since 1991 Swedish labor legislation has stipulated that injuries involving pupils at school are occupational injuries in the same sense as those incurred by people at work. ${ }^{1}$ As a result, with their 1.2 million pupils, ${ }^{2}$ Swedish schools have become one of Sweden's largest workplaces. Accordingly, new demands have been placed on the resources available for occupational injury research and prevention $\vec{\omega}$ and new challenges have been created. In particular, the unique nature of the schoolsw now to be regarded as the workplace of pupils $\overrightarrow{i r}$ makes it necessary to reassess instruments developed for more conventional occupationat injury surveillance.

It is our view that this extension of the occupational arena in Sweden necessitates three complementary steps: (1) the adaptation of the occupational injury paradigm to a newe target group, namely school pupils; (2) the implementation of a review of the relevanb literature on pupil injuries (an earlier reviews conducted by Gratz in $1992^{3}$ covered only five north American studies); and (3) an evaluation of already accumulated knowledge in the ligh? of the occupational injury paradigm. The review described below represents a firs attempt to come to grips with these steps and has a particular focus on the type (and. form) of information needed for surveillance purposes. It forms a part of a recentl established three year project now being con으 ducted in Sweden. The current paper presents the results of work carried out so far.

\section{An analytic frame for school injury} surveillance

An analytic frame for school injury prevention and in particular surveillance, is presented in the figure. Based on widely accepted lines of reasoning in the occupational injury arena, iE introduces a chain of four key concepts that from right to left, distinguish an injury from the accident sequence that precedes it, and the situational from the structural determinants of accident occurrence and the sustaining of atr injury. Both types of determinants are regardee as resulting from interactions between pupils $\Phi_{4}$ school environments, and the community.

This representation is inspired by what is

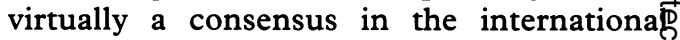
occupational accident literature, ${ }^{4-6}$ namely that a systemic perspective on injury investigations should be adopted in an occupational context Broadly speaking, this perspective implies the following: (1) a distinction between an injury and an accident; (2) a conception of an injurf as the culmination of a systematic, analyzable process rather than a sudden distinct event; and (3) a need to search for both situational and structural determinants in examining the causes of accidents and injuries. 


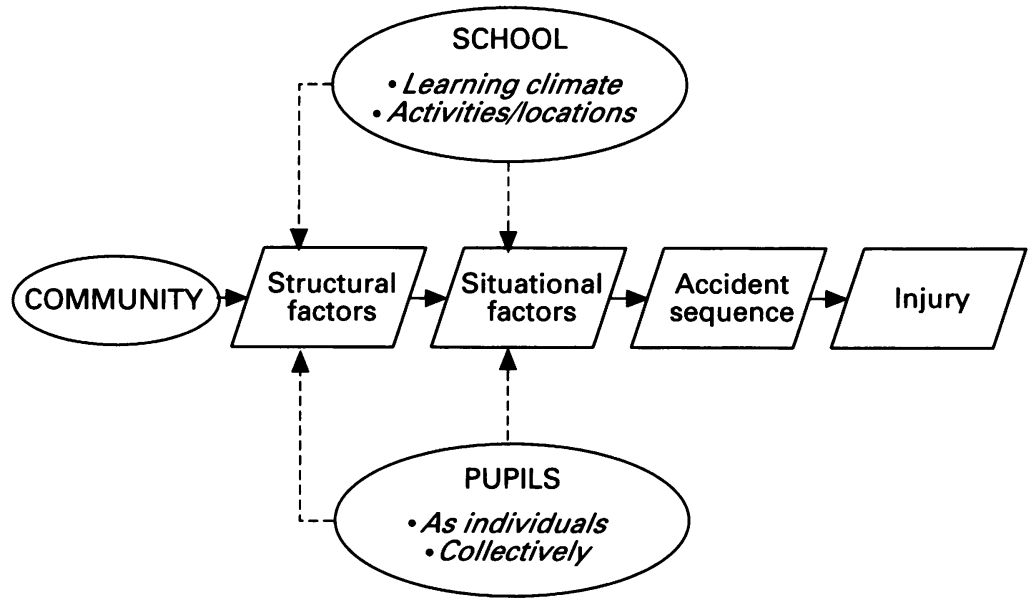

A frame for the analysis of school injuries.

THE SYSTEMIC APPROACH

This approach treats injury occurrence as the result of interactions between various components of a system, for example a 'man-machine system'. In its minimalist form, such a system encompasses individuals, their instruments, and their shared environment. Understanding the functioning of a system requires understanding of each component separately, and also the mechanisms and consequences of system-component interactions. The possibility of such interactions suggests that a system can never be defined solely as the sum of its individual parts.

From this perspective, sustaining an injury is regarded as a symptom of a malfunctioning system. In a work setting, this can take various forms, such as machine breakdowns, product defects, or physical injuries to human beings. It is through improving the functioning of the system as a whole that accident and injury prevention is envisaged to proceed. For this reason, factors involved in injuries, rather than causes of them, are sought for, and the perspective of injury investigation is widened from the injured individual (in this case a pupil) to his/her 'working' context. (A parallel to this can be found in Haddon's matrix. ${ }^{7}$ )

\section{THE DISTINCTION BETWEEN INJURY AND ACCIDENT SEQUENCE}

This distinction was originally introduced to the public health community by Haddon, ${ }^{7}$ and is now widely employed in research circles. ${ }^{8}$ Making the distinction, which is indirectly prompted by consideration of the systems' issue outlined above, has the merit of emphasizing that there are two different fields of investigation - and arenas for preventive intervention - in work safety. Injury analysis may offer clinical support and help define the corrective measures most urgently needed in a workplace. It can be regarded as being related to, and possibly a form of, tertiary prevention. By contrast, accident analysis (since it searches for the circumstances under which injuries are incurred and the mechanisms leading to them) may point to preventive action in the design of safety measures. Thus, it is primarily related to, or a form of, primary prevention. ${ }^{9}$

\section{THE INJURY PROCESS}

In the occupational literature, injuries tend to be regarded as the concluding phase of an accident process, which, in turn, is initiated by some disturbance to (or malfunction in) a system. From this perspective, an injury investigation is designed to identify a particular process under which injuries are sustained. Accordingly, the injury mechanism, the dynamics of injury event occurrence, and the influence of all possible actors involved, are considered. From a systems' perspective, investigations of this type are conducted because of the likelihood that there are some constants in the genesis of apparently different kinds of injuries. There may, for example, be similar circumstances, or background conditions common to different circumstances, of relevance to preventive interventions.

\section{SITUATIONAL AND STRUCTURAL INJURY DETERMINANTS}

Situational factors are ones that, at a given place and time, have the potential to trigger an accident sequence, and operate, by definition, through a change in the immediate environment. Examples in the school setting are a slippery walking surface, new equipment in the school yard, and a sudden lack of concentration on the part of a pupil or one of his/her schoolmates. Structural factors, by contrast, are more permanent 'traits' of the environment, and affect the likelihood of a temporary, situational change having an unfavorable consequence. For example, different walking surfaces give rise to differing levels of risk when it rains or snows.

In general terms, structural determinants define the basic - or latent - risk in a given environment, whereas situational factors determine the circumstantial - or temporary risk. In preventive terms, it can be stated that the greater the basic or permanent risk, the greater also is the risk that temporary hazards might initiate a sequence leading to injury. Thus, in principle, preventive measures to reduce the basic risk, that is measures directed at structural determinants, have longer lasting effects than those directed at situational factors. $^{4-6}$

\section{THREE INTERACTING AGENTS IN A}

SCHOOL SETTING: PUPIL, SCHOOL, AND COMMUNITY

As the figure indicates, both situational and structural determinants originate from interactions between 'actors'. In a school setting, there are three: pupil(s), school environments, and the community. The figure emphasizes that pupil(s) might contribute to injury event occurrence both individually and collectively and that the school ought to be viewed both globally, in terms of what we call its 'learning climate', and specifically, through the activities it arranges and the various locations where they are pursued. The community is an influence on both the pupil(s) and the school. 
A review of the literature dealing with school injuries relevant to surveillance Our review of the literature was oriented towards community based epidemiological studies dealing with all kinds of injuries to pupils at school. Our analytic focus was on how each aspect of the paradigm presented in the figure was addressed, findings of the studies that tended towards consensus, and what might need to be examined more closely in the future.

LITERATURE SEARCH, SELECTION, AND REVIEW Material was gathered through searches in a variety of databases, and through scrutiny of reference lists and lists of publications. Searches were made in the international databases: NIOSHTIC, MEDLINE, PSYCH INFO, SPRILINE, and Eric, and in the Swedish databases ARBLINE and SWEMED. The key words employed for all searches were 'accident/injury' in combination with 'school/ student/pupil/playground/athletics/sports'. The number of references obtained was so large that it was decided to restrict the material to just those papers where the key words were included in their title or summary.

A preliminary review of just over 300 articles was undertaken, generally by reading their abstract. All relevant articles (in English, French, Danish, or Swedish) were studied, but only refereed articles published in indexed international journals were considered for further analysis - a total of nearly 100 publications. For the current study, only 17 articles reporting the results of community based investigations of injuries involving pupils from several schools, and at different grades and levels, were scrutinized in detail. ${ }^{10-26}$ (Note that two were concerned with the same investigation. ${ }^{13}{ }^{15}$ ) We were not concerned with other, albeit related, kinds of articles, such as. those dealing with childhood injuries in alto possible environments, with one single schoo? level (for example primary school), with particular types of injuries or school activities? of a specific individual nature, or with solely methodological aspects.

For each study reviewed, information on the्ट following was gathered: type of study (retro 0 spective or prospective) and study period? (duration); size of the study population; datक source; variables compiled; statistics used; results obtained; and conclusions reached Attention was also paid to the inclusion and exclusion criteria employed to define an injury!̣

\section{RESULTS OF THE LITERATURE REVIEW}

Main features and injury rates
Table 1 summarizes the main features of the studies, the injury rates obtained, and thes differences observed, if any, between levels grades and between genders. The studies aree categorized as retrospective or prospective, and ordered alphabetically by name of author(s).

First, it can be observed that while moss studies lasted one (school) year, they useक different data sources and varied considerably: with regard to study population. Injury rates also showed considerable variation between $\overrightarrow{\vec{B}}$ studies, both retrospective and prospective, but the rates tended to be higher in the prospective studies. Moreover, although leve? and grade differences in injury rates were common, there was no consistent pattern to these differences.

Table 1 Basic information on the studies reviewed

\begin{tabular}{|c|c|c|c|c|c|c|}
\hline Study & $\begin{array}{l}\text { Duration of } \\
\text { the study (in } \\
\text { school years) }\end{array}$ & Data source & $\begin{array}{l}\text { Size of study } \\
\text { population }\end{array}$ & $\begin{array}{l}\text { Injury/1000 } \\
\text { pupils }\end{array}$ & $\begin{array}{l}\text { Difference in rate by } \\
\text { Level } \\
\text { (E: elementary } \\
\text { S: secondary) }\end{array}$ & $\begin{array}{l}\text { Gender } \\
\text { (M: male } \\
\text { F: female) }\end{array}$ \\
\hline \multicolumn{7}{|l|}{ Retrospective } \\
\hline Bell ${ }^{\circ}$ & 2 & School & $\begin{array}{r}900 \text { Pupils; } \\
4 \text { schools }\end{array}$ & 26 & $\mathrm{E}>\mathrm{S}$ & - \\
\hline $\begin{array}{l}\text { Langley et } a l^{17} \\
\text { Pagano et } \text { l }^{19}\end{array}$ & $\begin{array}{l}1 \\
5\end{array}$ & $\begin{array}{l}\text { Hospital } \\
\text { School }\end{array}$ & $\begin{array}{l}\text { NS } \\
\text { NS }\end{array}$ & $\begin{array}{r}2 \\
14\end{array}$ & $\begin{array}{l}\text { E>S } \\
\text { Decrease with grade }\end{array}$ & $\begin{array}{l}\text { None } \\
M>F\end{array}$ \\
\hline Sheps and Evans ${ }^{22}$ & 2 & School & $\begin{array}{l}53777 \text { Pupils; } \\
108 \text { schools }\end{array}$ & $\begin{array}{l}14 \\
28\end{array}$ & Inverted U with grade & - \\
\hline Taketa $^{24}$ & 1 & School & $\begin{array}{l}157000 \text { Pupils; } \\
204 \text { schools }\end{array}$ & 17 & $\begin{array}{l}E>S \text { inverted } U \\
\text { with grade }\end{array}$ & $M>F$ \\
\hline Yamanaka $^{26}$ & 1 & Insurance & $\begin{array}{l}24 \text { Million pupils; } \\
80000 \text { schools }\end{array}$ & 46 & Inverted U with grade & - \\
\hline \multicolumn{7}{|l|}{ Prospective } \\
\hline $\begin{array}{c}\text { Bergström and } \\
\text { Björnstig }\end{array}$ & 1 & Hospital & $\begin{array}{l}13733 \text { Pupils; } \\
60 \text { schools }\end{array}$ & 22 & None & None \\
\hline Boyce et al ${ }^{2}$ & 2 & School & $\begin{array}{l}54873 \text { Pupils; } \\
99 \text { schools }\end{array}$ & 49 & Inverted U with grade & $\mathrm{M}>\mathrm{F}$ \\
\hline $\begin{array}{l}\text { Feldman et al }{ }^{13} \\
\text { Hodgson et al }\end{array}$ & 1 & School & $\begin{array}{r}83692 \text { Pupils; } \\
212 \text { schools }\end{array}$ & 54 & $E>S$ & $M>F$ \\
\hline $\begin{array}{l}\text { Hammarström } \\
\text { and Janlert }^{14}\end{array}$ & 1 & Hospital & $\begin{array}{r}23239 \text { Pupils; } \\
132 \text { schools }\end{array}$ & 24 & $S>E$ & $\mathrm{M}>\mathrm{F}$ \\
\hline Jacobsson et $a^{16}$ & 1 & Hospital & $\begin{array}{l}4882 \text { Pupils; } \\
17 \text { schools }\end{array}$ & 38 & $\begin{array}{l}\mathrm{S}>\mathrm{E} \text { increase with grade } \\
\text { in } \mathrm{E}\end{array}$ & $\mathrm{M}>\mathrm{F}^{\star}$ \\
\hline Lenaway et al ${ }^{18}$ & 1 & Insurance & $\begin{array}{l}5518 \text { Pupils; } \\
9 \text { schools }\end{array}$ & 92 & Increase with grade & $M>F$ \\
\hline $\begin{array}{l}\text { Petridou et al }{ }^{19} \\
\text { Schelp et al } l^{11}\end{array}$ & $\begin{array}{l}1 \\
3\end{array}$ & $\begin{array}{l}\text { Hospital } \\
\text { Hospital }\end{array}$ & N387 Pupils; & - & Increase with grade & $\begin{array}{l}- \\
-\end{array}$ \\
\hline Sillanpää et $a l^{23}$ & 1 & School & $\begin{array}{l}23296 \text { Pupils; } \\
72 \text { schools }\end{array}$ & 304 & $E>S$ & $M>F$ \\
\hline Woringer $^{25}$ & 1 & $\begin{array}{l}\text { School and } \\
\text { parents }\end{array}$ & $\begin{array}{l}11700 \text { Pupils; } \\
\text { NS schools }\end{array}$ & 67 & Vary with severity & None \\
\hline
\end{tabular}

^In upper high school

A dash indicates no denominators, not specified, or not studied. NS: not specified. 
When differences were observed, it was often preadolescents (in lower secondary school) who were at greater risk. Some U and inverted $U$ curves were obtained when number of injuries was related to school grade. Woringer's study reveals that minor injuries are more frequent in elementary school, but that severe injuries increase in occurrence with age, being most frequent among preadolescents. This produces a kind of inverted $U$ curve for the relationship between injury and grade. ${ }^{25}$

All injuries aggregated, boys, generally but not consistently, were found to be at greater risk than girls. But there are conflicting results concerning severity. One study indicates that gender differences are less apparent in the case of severe injuries than all injuries aggregated, ${ }^{13}$ whereas another suggests that gender differences are disguised by aggregation. Female puplis may face a greater risk of severe injury, in particular at secondary school level. ${ }^{25}$

\section{Ecological characteristics}

Only three studies looked at ecological characteristics of schools as potential injury determinants. In the study conducted by Boyce et al it was found that longer school hours, alternative curriculums, less experienced school nurses, and lower pupil-to-staff ratios were significant determinants of higher injury rates. ${ }^{12}$ Bergström and Björnstig found a negative correlation between school injury rate and the distance between the school and the nearest hospital. ${ }^{11}$ These researchers found no relation between injury rate and any of the following factors: size of school, age of school building, high migration area, social problems, special education support, or percentage of students bussed to school. In Bell's study lack of supervision in the playground was associated with higher injury rates ${ }^{10}$ (see also Bijur, ${ }^{8}$ Feldman et $a l,{ }^{13}$ and Woringer ${ }^{25}$ ).

From a different perspective, the study conducted by Woringer revealed that injury rates were higher in 'special' classes (that is classes that had been reduced in size, or classes for children with developmental problems) than in other classes, in both primary and secondary schools. ${ }^{25}$ Also, severe injuries were incurred substantially more frequently in these classes.

\section{Socioeconomic and family related factors}

Little attention has been paid to socioeconomic and family related factors. However, the study conducted by Petridou et al measures the effects of certain socioeconomic and family related injury variables. ${ }^{20}$ Their study revealed that low level of parental education (on the part of the father), family disruption (single parenthood), and poor performance at school (on the part of the child) are strong correlates of school injury experience. It showed also that having sustained a previous injury requiring medical attention is a significant predictor of subsequent injury. By contrast with Petridou et al, however, Bergström and Björnstig found that social problems, chronic illness, and stressful events in the family or school were not any more common among injured pupils than pupils in general.

\section{Hazardous school activities and locations}

Most studies tried to define the school activities and locations where injuries tended to be sustained. The playground, as a site, and sports, as an activity, appeared to be more hazardous than other sites and activities. The playground tended to be more critical in elementary school or kindergarten, ${ }^{10-1217-1922-2426}$ whereas sport activities and locations were more important in general (all grades aggregated) and for other grades. ${ }^{10-12} 17-1922-26$

It should be emphasized that these conclusions have been drawn despite considerable variation between studies in the categorization of locations and activities. In some, in fact, location and activity variables are confused. While some authors talked about sports as an activity ${ }^{10-1218}$ or about physical education, 142326 others combined sports and breaks (or sports and play) 161722 or breaks and physical education. ${ }^{21}$ Some referred to sport related areas, ${ }^{22}$ gym areas, ${ }^{18}{ }_{19}$ combined athletics and athletic fields, ${ }^{12131518}$ or spoke of 'breaks' as an activity at risk. ${ }^{21}$

The definition of sport related activities or locations at risk also varied: gymnastics was used either alone 1113151826 or grouped with other activities. ${ }^{21}$ Similarly, the athletic field was used alone ${ }^{18}$ or together with the gymnasium $^{24}$ or physical education. ${ }^{23}$ Taking the studies as a whole, a tendency was observed for ball sports (for example basketball, soccer, volleyball, or baseball) to be more strongly related to injury than other sports. ${ }^{11} 13151826$

Woringer studied gender differences by school grade and school activities (classified as classroom activities; sport activities, not organized by adults, but on the school site; and others) and suggests that, in primary school, unorganized activities (inside and outside, during breaks) are more hazardous, and that boys are more at risk than girls. By contrast, in secondary school, sport activities (gymnastics, skating, or swimming) are more critical, and girls are more at risk.

Most frequent causes of injury and types of interaction between pupils

Causes of injury were identified in three studies. ${ }^{161722}$ In all instances, falls were the most frequent cause. Being struck by or caught between objects was also a frequent cause, coming before 'excessive physical exercise' in one study ${ }^{16}$ and after 'mechanical or object related injuries' in another. ${ }^{22}$

Woringer ${ }^{25}$ coded 'type of interaction between pupils' at the time of injury and found that 'no interaction' and 'game' were the most common injury circumstances, in both sexes and in both elementary and secondary school. Game related injuries were twice as frequent in secondary school as in elementary school among girls, and slightly more frequent among boys. 
Most frequent types of injury

Table 2 lists the 10 studies that examined injury types. For each study, the table specifies the categories of pupils or locations (second column) that correspond to the most frequent type of injury (third column), as described by the authors.

Lenaway et $a l^{18}$ and Pagano et $a l^{19}$ made the most extensive efforts to differentiate injury type by group of pupils or location. The most frequent type of injury, all pupils aggregated (referred to as 'in general' in second column), varies between studies. The coding (or grouping) used for type of injury varies substantially from one study to another, making comparisons difficult. However, there seems to be a tendency for type of injury to vary with school grade and level, or with location. Sports, for instance, are more often associated with sprains/strains and fractures.

Table 2 Most frequent types of injuries

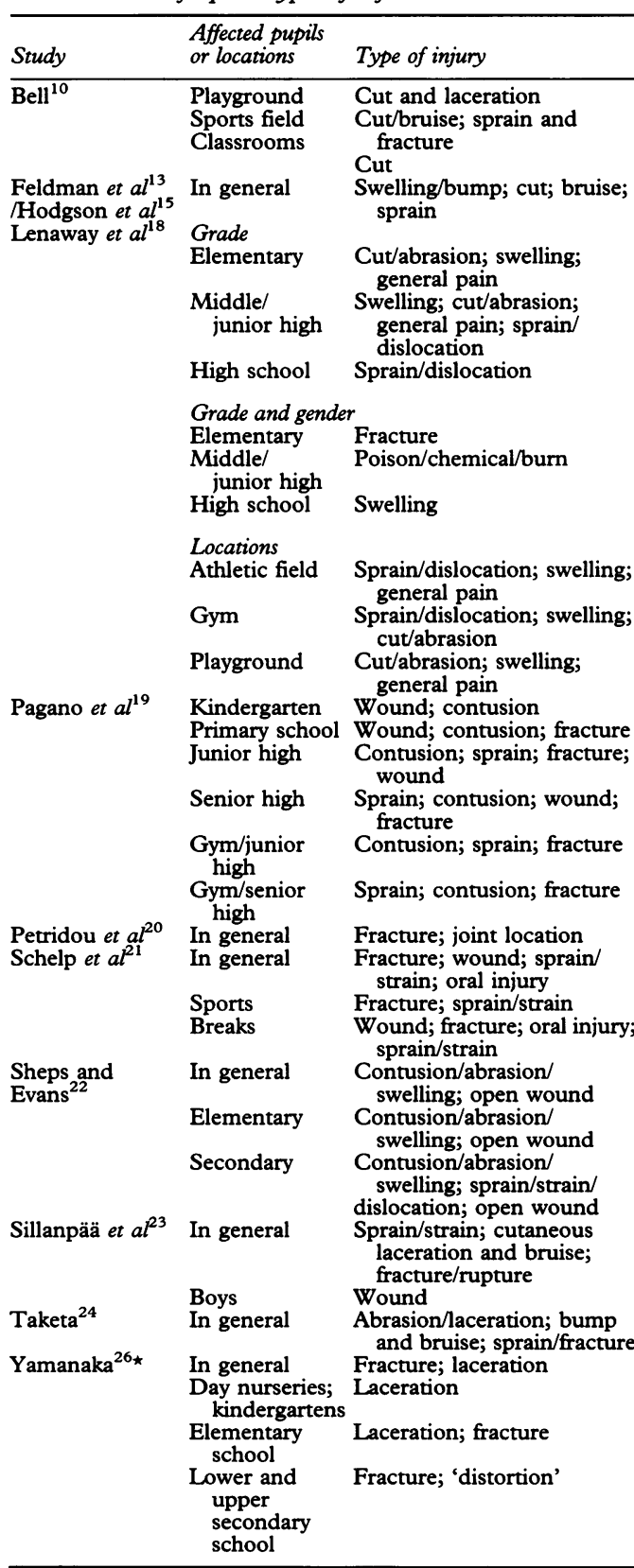

*Results based on an analysis of injuries in a prefecture, not the whole country ( $n=28791)$.
The results of Lenaway et al suggest that a large proportion of injuries sustained on the athletic field or in the gymnasium are similar by nature, and also affect the same parts of the body. B. contrast, the nature of playground injuries varies, as does the part of the body affected.

Parts of the body most frequently injured

Table 3 lists the nine studies that specified the part of the body injured most frequently b group, location, or activity.

The tables reveal considerable variation§ between studies in the classification of activ ities and locations, and in the manner in which parts of the body injured are categorizedw. There is little evidence of a strong relationship between school level and/or location and bod\% part injured. Head injuries, however, seem to be sustained more frequently in the playo ground, while injuries to the lower and uppe? extremities are most frequently incurred during sports.

Table 3 Most frequent parts of body injured

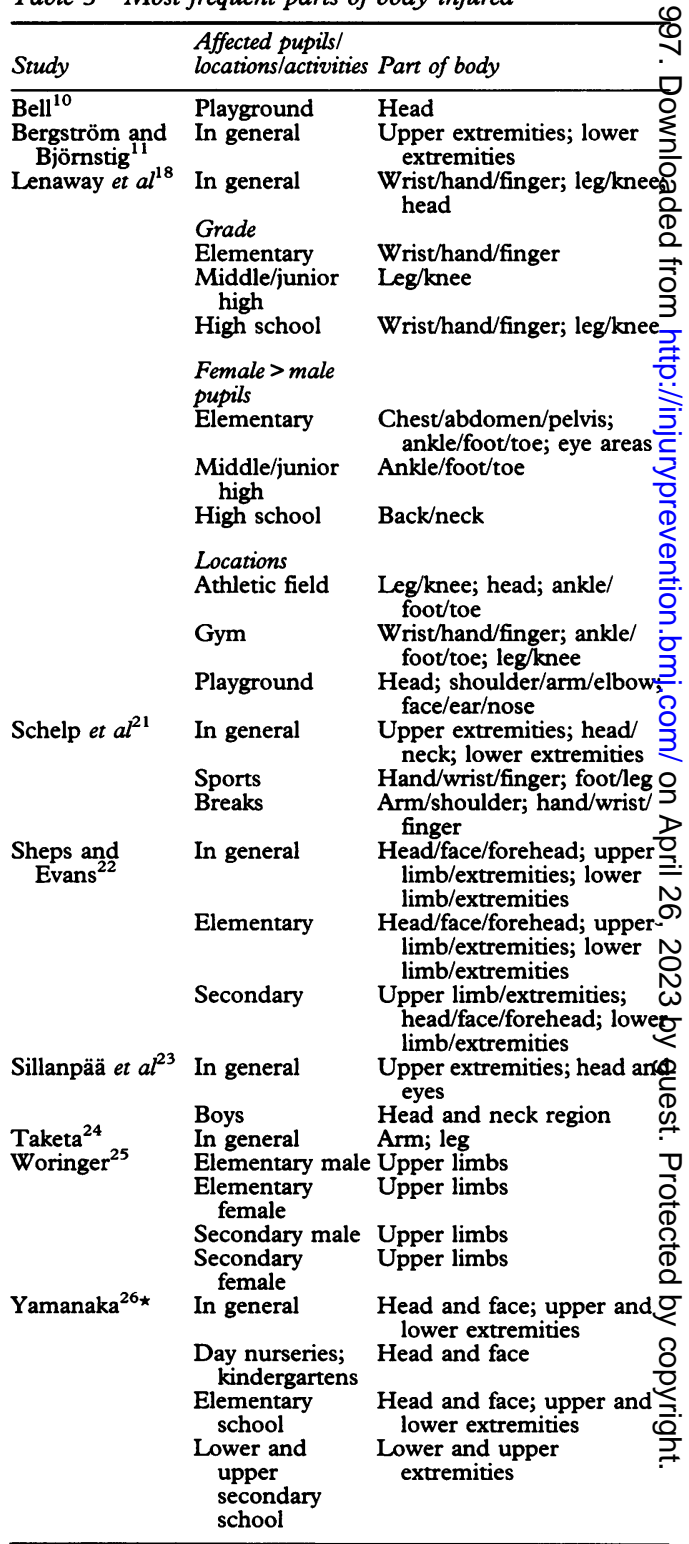

* Results based on an analysis of injuries in a prefecture prefecture, not the whole country $(n=28791)$. 
Seasonal differences

Seasonal differences in injury rates were considered in five studies, ${ }^{101823-25}$ but no consistent pattern emerges.

\section{Discussion}

For reasons that have been only sparsely investigated, injury rates and injury severity tend to vary considerably from school to school. ${ }^{11} 12$ They also tend to vary with school level and grade, but not always in the same direction. Recreational and sport areas are the locations where injuries occur most frequently, the playground being a risk area for young pupils, with organized gymnastics and sports tending to become more important with age.

Preadolescents tend to constitute a group at high risk, and gender differences are common among all age groups. Boys are generally at higher risk than girls, but less obviously so in the case of severe injuries ${ }^{13} 25$ and as school level increases, ${ }^{14}$ and not in all types of activities. ${ }^{25}$ Further, it is not clear whether educational and behavioral correlates of low socioeconomic status and single parenthood are strong determinants of school injuries.

Injury types, and parts of the body injured, vary with school grade, age of pupil, and school activity. Some trends are more obvious when activity is considered, particularly in the case of sports. Severe injuries are rare at all levels.

\section{METHODOLOGICAL ISSUES: QUANTITATIVE} AND QUALITATIVE COMPARABILITY PROBLEMS Community based epidemiological studies of injuries at school have a number of characteristics that make them difficult to compare. Quantitatively, the rates obtained are influenced by at least three parameters: type of study, site of data collection, and type of event considered.

A prospective research design, as opposed to a retrospective one, improves the effectiveness of numerator data (injury data) collection, ${ }^{827}$ but only provided that the study period is short. ${ }^{28}$ In addition, school based data collection, as opposed to emergency clinic, hospital based, or insurance based collection, increases the total number of 'cases'. Reporting is easier and a wider range of degrees of severity can be identified. ${ }^{82627}$ It should be noted that some studies had restrictive inclusion criteria for injuries $^{12}$ whereas others encompassed not only injuries that had occurred on the school site but also on the trip to or from school. ${ }^{710111416-2126}$ Woringer was the only researcher to make consistent comparisons between genders and school grades based on three categories of injury severity. ${ }^{25}$

There were also qualitative differences between the studies with regard to type of information collected and the manner in which it was coded. This is particularly evident in the case of higher risk school activities and locations. Comparability problems also arose because of the way in which some injury descriptors were coded. This applied, above all, to type of injury and body part, but also to cause of injury (or injury mechanism).

\section{QUESTIONS LEFT UNANSWERED AND WHAT}

SURVEILLANCE MIGHT ACHIEVE

In the light of the analytic frame presented above, constructed from an occupational injury perspective, it is evident that there is much more to learn with regard to injuries at school. Better understanding of the mechanisms giving rise to school injury requires answers to certain key questions, listed below. Note that they concern both the structural and situational determinants of injury (see figure):

- Are there some types of communities that have higher injury rates than others and, if so, what are their (structural) characteristics?

- Which (structural) characteristics of schools (demographic, social, curriculum related or physical) are the strongest predictors of injury occurrence?

- Are there some (structural) individual characteristics - other than gender and agethat are strong injury predictors, and if so, under what circumstances and to what types of injuries do they apply?

- Is the injury risk faced by an individual pupil affected by the nature of intragroup interaction in school (structural and situational factors)?

- How are injuries incurred? Are there typical injury patterns and accident sequences?

Interestingly, the final three questions were chosen as the ones of greatest importance in the course of a recent Swedish symposium involving 120 practitioners and researchers. Problems related to pupil injuries and the school environment in general were extensively discussed. ${ }^{2}$

Clearly, well conceived surveillance systems might provide answers, at least in part, to several of these questions, and could, therefore, serve both as an aid to prevention and a guide to further research. The development of surveillance systems would benefit from the adoption of two approaches. First, there is a need to establish a core set of mutually exclusive variables illuminating accident sequences. Important variables to be taken into consideration are injury location, activity being undertaken at the time of injury, accident event (the trigger of the accident sequence), injury mechanism, causal agent, type of injury, and part of the body injured. The type of interactions between pupils is a further aspect to be examined..$^{25}$ Second, these core data should be looked at from a multidimensional perspective to identify patterns in injury characteristics and circumstances of occurrence. (Examples from the occupational injury arena can be found in Laflamme et $a ._{.}{ }^{2930}$ )

It is also important to point out, as emphasized in Graz's review, ${ }^{3}$ that the quality of these data will depend largely on the interest and commitment that can be created in the schools and among all the groups involved (on this issue, see also $\mathrm{Menckel}^{2}$ ). 


\section{Conclusion}

The school is one of the most significant learning environments of tomorrow's workers and adult citizens. It is, therefore, of great importance for the promotion of people's physical and mental wellbeing and to help children develop in safe environments. Progress with regard to safety awareness (risk consciousness), not least in the occupational environment, will depend on this.

There may be considerable merit in regarding school children as workers. The occupational injury paradigm presented here, and instruments of workplace surveillance, have much to offer injury prevention both theoretically and practically. Naturally, adaptations would have to be made for them to be applicable in the school context.

This review of community based epidemiological studies of school injuries highlights certain risk groups and some particularly hazardous school activities and locations. It provides little information, however, on the reasons why, and the circumstances under which, particular groups or activities are more at risk. The review also shows that studies conducted so far have paid more attention to the injuries than to the circumstances under which they are incurred. But, long lasting injury prevention strategies require a wider perspective. In the light of the frame of analysis presented in the current study, further attention in future research needs to be allocated to the part played by the community, the school, and the pupil in injury event occurrence. Greater attention should also be paid to specific accident contexts revealed by the review, including sports injuries among various age groups, and injuries incurred in unorganized and non-supervised playground activities.

This review was funded by Sweden's National Institute of Public Health.

1 The Swedish Work Environment Act. Stockholm: Almanaför-

laget, 1991 .
2 Menckel E, ed. Skololycksfall och skolansyterum. Fakta, forskningsfrågor och förebyggande exempel. Stockholm: forskningsfragor och forebyggar

3 Gratz RR. School injuries: what we know, what we need. fournal of Pediatric Health Care 1992; 5: (part 1): 256-62 Laflamme L. A better understanding of occupational accident genesis to improve safety in the workplace. fournal of Occupational Accidents 1990; 12: 155-65.

5 Laflamme L. Occupational accidents-from comprehension to prevention. In: Menckel E, Kullinger B, eds. Fifteen years of occupational accident research in Sweden. Stockholm: Swedish Council for Working Life, 1996: 37-48. 6 Menckel E, Kullinger B. Twenty researchers summarize fifteen years of Swedish occupational-accident research. In: Menckel E, Kullinger B, eds. Fifteen years of occupational accident research in Sweden. Stockholn. Swedish Council for Working Life, 1996: 7-17.

7 Haddon W Jr. Advances in the epidemiology of injuries as basis for public health policy. Public Health Rep 1980; 95 $411-21$.

8 Bijur PE. What's in a name? Comments on the use of the terms 'accident' and 'injury'. Injury Prevention 1995; 1: 9 .

9 Avery JG. Accident prevention-injury control-injury prę vention - or whatever. Injury Prevention 1995; 1: 10-1. 10 Bell K. School accidents. Health Bull (Edinb) 1986; 2: $99 \overline{\bar{\omega}}$

11 Bergström E, Björnstig U. School injuries. Epidemiology an clinical features of 307 cases registered at hospital during one school year. Scand f Prim Care 1991; 9: 209-16.

12 Boyce T, Sprunger LW, Sobolewski S, Schaefer C. Epidemiology of injuries in a large, urban school distric Pediatrics 1984; 74: 342-9.

13 Feldman W, Woodward CA, Hodgson C, Harsanyi Milner R, Feldman E. Prospective study of schoc injuries: incidence, injuries: incidence, types, related factors and initia
management. Can Med Assoc $\mathcal{F} 1983$; 129: 1279-83.

14 Hammarström A, Janlert U. Epidemiology of school injuries in the noarthern part of Sweden. Scand $\mathcal{F}$ Soc Med $1994 ;$ 22. $120-6$

15 Hodgson C, Woodwart C, Feldman W. A descriptive studP of school injuries in a Canadian region. Pediatric Nursing 1984; 3: 215-20.

16 Jacobsson B, Bek-Jensen H, Jansson B. One year's incidence $\overrightarrow{-}$ of school accidents and their severity in a Swedis municipality. Scan $\mathcal{F}$ Prim Health Care 1986; 4: 213-7.

17 Langley JD, Chalmers D, Collins B. Unintentional injuries to students at school. 7 Paediatr Child Health 1990; 26: $323-8$.

18 Lenaway DD, Ambler AG, Beaudoin D. The epidemiolote of school-related injuries: new perspectives. $A m \ngtr$ Prev Med 1992; 8: 193-8.

19 Pagano A, Cabrini E, Anneli M, Bernuzzi S, Lopiccoli SO Fischer P. Accidents in the school environment in Milan A five year survey. Eur $₹$ Epidemiol 1987; 2: 196-201.

20 Petridou E, Kouri N, Trichopoulos D, Revinthi K, Skalkidi $Y$, Tong D. School injuries in Athens: socioeconomic an family risk factors. $\mathcal{F}$ Epidemiol Community Health 1998 48: $490-1$.

21 Schelp L, Ekman R, Fahl I. School accidents during a thre $\overrightarrow{\overline{\vec{E}}}$ school-years period in a Swedish municipality. Publiz Health 1991; 105: 113-20.

22 Sheps SB, Evans GD. Epidemiology of school injuries: a 2 year experience in a municipal health departmento Pediatrics 1987; 79: 69-75.

23 Sillanpää $M$, Terho $P$, Westerén $H$, Pisirici $H$. Accidents i schoolchildren: epidemiologic, aetiologic and prognostic choolchildren: epidemiologic, aetiologic and prognostic $119-30$.

24 Taketa S. Student accidents in Hawaii's public schools. $\Phi$ School Health 1984; 54: 208-9.

25 Woringer V. Les accidents scolaires. Rev Med Suisse Romande 1995; 115: $153-6$.

26 Yamanaka $T$. Injuries of school-aged children in Japant causes and costs. Acta Paediatr Fpn 1993; 35: 201 - 6.

27 Woodward J, Milner R, Harzsanyi Z, Feldman W, Feldma W, Hodgson C. Completeness of routine reporting of school-related injuries to children. Can 7 Public Healt? 1984; 75: $454-7$.

28 Bremberg $S$. Is school-based reporting of injuries at school reliable? A literature review and an empirical study. Acci $\$$ reliable? A literature review

29 Laflamme L Backström T, Döös M. Typical acciden encountered by assembly workers: six scenarios for safety planning identified using multivariate methods. Accid Anal Prev 1993; 25: 399-410.

30 Laflamme L, Döös M, Backström T. Identifying accident patterns using the FAC and HAC: their application to accidents at the engine workshops of an automobile and truck factory. Safety Science 1991; 14: 13-33.

\section{Bathtub drowning}

A 9 month old boy died after being found submerged in nine inches of bathwater. The mother had left the infant and two siblings unattended to get a towel (Hartford, AP, 18 May 1996) (AG).

\section{Fatal window crash}

After crashing through a window during a netball practice, a 12 year old girl in New Zealand died of her injuries. The girl was racing after a ball and crashed head first through the window. Authorities are wondering if this was a preventable accident (ODT, 13 May 1996) (DC). 